\title{
Dança escolar: uma possibilidade na Educação Física
}

Chames Maria Stalliviere Gariba* Ana Franzoni**

\begin{abstract}
Resumo: O presente artigo retrata reflexões a respeito da dança, sua atuação na sociedade, sua compreensão associada ao processo educacional. Destaca informações primordiais que devem ser abordadas e discutidas com o professor de Educação Física, voltadas para o processo de compreensão corporal através da dança, como possibilidade de estabelecer múltiplas relações com outras áreas do conhecimento. Ressalta os enfrentamentos, bem como as barreiras a serem ultrapassadas, para que a dança esteja cada vez mais inserida no ambiente escolar. Essas discussões referendam o compromisso que se deve ter, como educador, na busca de uma prática pedagógica voltada para a formação de cidadãos críticos, autônomos e conscientes de seus atos, para uma transformação social.
\end{abstract}

Palavras-chave: Dança. Educação Física. Ensino. Evolução cultural.

\section{INTRODUÇÃO: DANÇA NO CENÁRIO HISTÓRICO}

Ao se analisar a vida de qualquer civilização, desde as mais remotas até a dos dias atuais, verificam-se entre as expressões culturais atividades como jogos, desportos e dança. Para manifestar suas emoções e exteriorizá-las, o homem recorreu ao movimento, ao gesto que, de acordo com Fahlbusch (1990), é a dança, em sua forma mais elementar. A dança e a sociedade estão sempre imbricadas. Não há como falar da dança sem percorrer a grandeza de sua trajetória ao longo dos anos, nem deixar de falar do homem, da sua corporeidade e necessidades. É importante resgatar as dimensões desse saber, já que a dança é parte integral desse processo, devido à inseparabilidade na relação desta com a história humana.

* Doutoranda do curso de Engenharia e Gestão do Conhecimento pela Universidade Federal de Santa Catarina (UFSC). Mestre em Engenharia de Produção na área do Empreendedorismo pela UFSC. Licenciada em Educação Física pela UDESC. Coordenadora de Projetos educativos, incluindo o projeto de Dança Escola Rede em Dança, da Secretaria Municipal de Educação de Florianópolis. E-mail: gariba@pmf.sc.gov.br

** Orientadora e Docente do Curso de Pós-Graduação em Engenharia e Gestão do Conhecimento na UFSC. E-mail: afranzoni@gmail.com 
Era por meio da expressividade que o homem primitivo demonstrava sua relação consigo próprio, com o outro e com a natureza. Essa foi sua forma de manifestação social e que serviu para auxiliá-lo a afirmar-se como membro da sua sociedade.

Observa-se isso nas afirmações de Oliveira (2001, p.14), quando menciona que:

\begin{abstract}
Uma das atividades físicas mais significativas para o homem antigo foi a dança. Utilizada como forma de exibir suas qualidades físicas e de expressar os seus sentimentos, era praticada por todos os povos, desde o paleolítico ${ }^{1}$ superior (60.000 a.C.).
\end{abstract}

A dança tinha características lúdicas e ritualísticas, nas quais ocorriam manifestações de alegria pela caça e pesca ou dramatizações pelos nascimentos e funerais. Percebe-se que os acontecimentos importantes e significativos, na sociedade antiga, ocorriam com uma constante participação corporal. Nanni confirma isso quando cita que:

As danças, em todas as épocas da história e/ou espaço geográfico, para todos os povos é representação de suas manifestações, de seus "estados de espírito", permeios de emoções, de expressão e comunicação do ser e de suas características culturais. (NANNI, 2003, p.7)

O conhecimento de si mesmo e da dança, portanto, passa pela necessidade de conhecer sua própria história e as manifestações culturais de seu povo. Nesse sentido, a dança sempre visou acontecimentos importantes da própria vida, da saúde, da religião, da morte, da fertilidade, do vigor físico e sexual, também permeando os caminhos terapêuticos, artísticos e educacionais, estabelecendo assim, uma diversidade interessante para essa manifestação. Dessa forma, a dança se insere no universo cultural, expressando significados, simbolizando a existência humana.

Robinson (1978), para expressar as várias aplicações e a gênese da dança no mundo contemporâneo, elaborou um diagrama indicado

\footnotetext{
${ }^{1}$ Época em que o homem procurava por alimentos e lutava pela sobrevivência (SBORQUIA e GALLARDO, 2006, p.14).

Movimento, Porto Alegre, v.13, n. 02, p.155-171, maio/agosto de 2007.
} 
por ela de árvore da dança, exposto na Figura 1, demonstrando sua classificação. Alguns autores, como Strazzacappa (2001) e Sborquia e Gallardo (2006), também se apropriaram desse conhecimento em suas pesquisas, evidenciando a importância desse estudo.

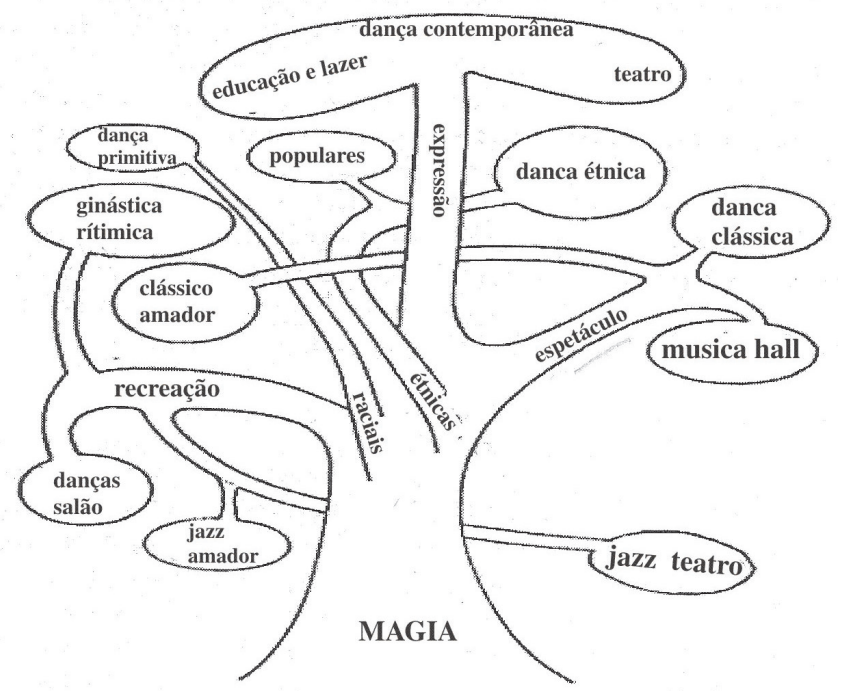

Strazzacappa (2001) reconhece que o desenho dessa árvore mostra, de forma clara, as várias ramificações que fazem parte do universo da dança, no qual adquirem diversas funções a partir de três motivações principais, a saber: a expressão, a recreação e o espetáculo. No tronco, observa-se que todas estão interligadas e são geradas pela magia que acontece por meio das relações do ser humano com a sociedade (ROBINSON, 1978).

O mesmo autor argumenta que a expressão é a motivação essencial da dança, representada na árvore pelo tronco primordial. Nesse tronco, situam-se o teatro, a dança contemporânea, a educação e o lazer, cujo contorno se faz com uma bifurcação para a recreação e outra para o espetáculo, em que estão as danças populares.

Conforme Robinson (1978) fez essa seção haja vista, essas manifestações poderem representar a expressão de uma comunidade,

Movimento, Porto Alegre, v.13, n. 02, p.155-171, maio/agosto de 2007. 
ou ainda, serem realizadas como forma de espetáculos. Existem também, as manifestações populares, que não perderam seu caráter original, chamadas por Robinson de danças primitivas, dentre elas a recreação e a expressão.

No tronco da recreação, encontram-se as danças de salão, a ginástica rítmica e o jazz, todas praticadas sem objetivo profissionalizante. Strazzacappa (2001), em uma tentativa de atualizar a árvore, acrescentou outras danças, dentre as quais: as danças populares brasileiras (como o forró, o samba, o axé), a valsa, o tango, o bolero que também estão incluídas como danças de salão; as danças consideradas regionais e provenientes de países específicos, como a dança do ventre, a flamenca, o sapateado, a dança de rua. Essas, segundo Strazzacappa (2001), introduzem-se na expressão e ramificam-se, tanto para a área da recreação, de forma amadora, como para o campo profissional do espetáculo.

Com essa classificação, fica clara a inserção da dança tanto no campo profissional, como no educativo, no amador e também no das manifestações culturais. Essa atuação está mais bem visualizada na Figura 2.

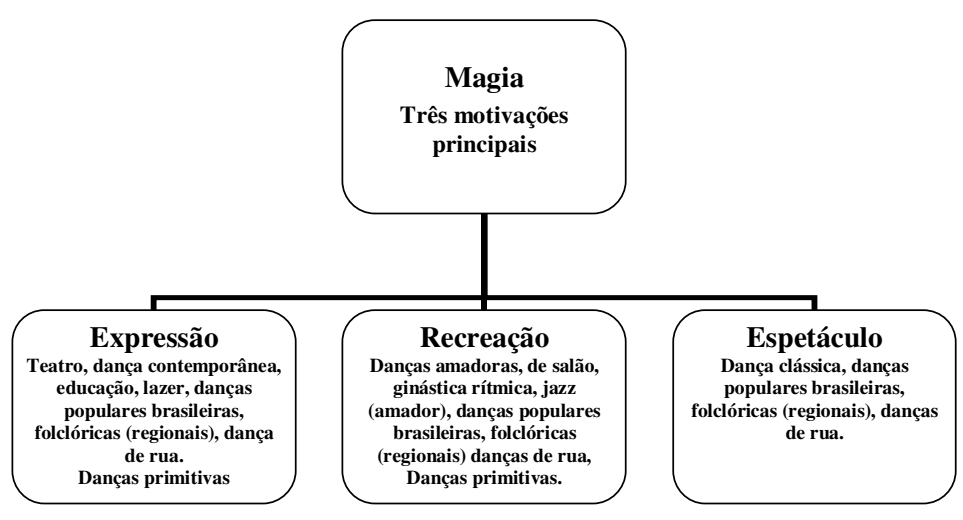

Figura 2: Organograma da classificação da dança Fonte: Adaptado de Robinson (1978) e Strazzacappa (2001).

Movimento, Porto Alegre, v.13, n. 02, p.155-171, maio/agosto de 2007. 
O que se pode inferir, entretanto, dessas concepções é que o mais importante não é o campo de trabalho a ser escolhido por meio de um ou outro estilo, mas de que forma se pode trabalhar com os elementos considerados importantes para o desenvolvimento do ser humano. Dessa forma, a questão base que aqui se coloca é a relevância desse trabalho para despertar no homem - que de nômade a sedentário, oprimido pelo tempo e espaço, pelas situações cotidianas - o interesse pela dança como espaço democrático, rompendo com a idéia de que é privilégio de alguns (GARIBA, 2002); e que é necessária uma técnica específica, para executá-la. Cabe frisar que isso implica um repensar de conceitos que se distanciam da dança apenas como arte tradicional. ${ }^{2}$

Entende-se que o fundamental é ser capaz de compreender a dança como uma linguagem que, para além de permear o processo de produção do conhecimento e a inserção da práxis social, prioriza não só esse processo de construção, mas também os resultados dele advindos, remetendo-os a momentos preciosos, capazes de despertar a consciência crítica de quem os vivencia.

Nessa tessitura, a dança enquadra-se como linguagem que deve ser ensinada, aprendida e vivenciada, na medida em que favorece o desenvolvimento de vertentes cognitivas, éticas e estéticas e contribui qualitativamente para as questões da socialização e expressão. Atividades corporais advindas da expressividade, comunicação, alegria, liberdade são elementos relevantes na vida do ser humano.

Essa compreensão insere a dança no conceito de movimento e, como tal, pode estar cada vez mais inserida em vários contextos sociais, partindo-se do princípio que é indispensável para o indivíduo entender o quê e por que fazer o movimento expressivo que, antes de tudo, deve ser consciente.

\footnotetext{
${ }^{2}$ No texto, o sentido de arte tradicional refere-se às danças incorporadas na sociedade contemporânea tidas como modelos ou padrão para o ato de dançar, como por exemplo o ballet clássico.

Movimento, Porto Alegre, v.13, n. 02, p.155-171, maio/agosto de 2007.
} 
Ao fazer alusão ao movimento consciente, Oliveira aponta que:

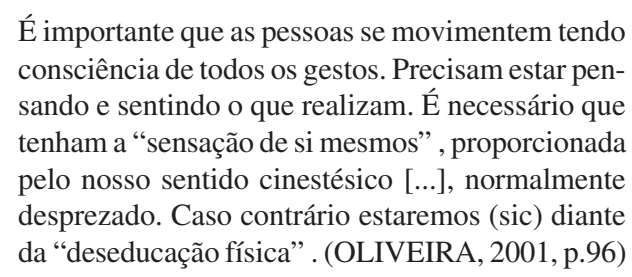

Em assim sendo, essa consciência situa o homem como um ser no mundo, delineando sua interação como sujeito de sua práxis, ao desvelar a sua realidade histórica, por meio de sua corporeidade (NANNI, 1998). Assim, situar-se como sujeito significa construir uma integração constante com o contexto sócio-histórico, no qual está inserido, em uma visão de corpo participante e não corpo biológico, ${ }^{3}$ ou seja, o ser humano deixa de ter um corpo para ser um corpo.

Buscar uma prática pedagógica mais coerente por meio da dança consiste em possibilitar ao indivíduo expressar-se criativamente, sem exclusões, tornando essa linguagem corporal transformadora e não reprodutora. Nesse contexto, diversos autores como Barreto (2004), Saraiva et al. (2005), Sborquia e Gallardo (2006), entre outros, têm a visão de que é a partir do processo criativo, desenvolvido pela dança na escola, que o indivíduo emancipa-se.

Partindo do mesmo pressuposto, Strazzacappa e Morandi (2006) ressaltam que quando a dança estiver inserida em muitas escolas, infiltrada por todas as portas e janelas, talvez se consiga perceber os reflexos e as implicações das relações estabelecidas entre ela, a educação e a sociedade.

Diante das afirmações feitas, a dança, então, pode ser uma ferramenta preciosa para o indivíduo lidar com suas necessidades, desejos, expectativas e também servir como instrumento para seu desenvolvimento individual e social. Nessa perspectiva, pode-se

${ }^{3}$ Este significado representa que o corpo não se reduz ao mero corpo físico, mas é condição de estar no mundo, participar, relacionar-se e construir-se nas relações sócio-históricas (SURDI, 2001).

Movimento, Porto Alegre, v.13, n. 02, p.155-171, maio/agosto de 2007. 
considerar a dança como uma fonte de percepção, entendendo-se que a elaboração do conhecimento passa pelo corpo. Assim sendo, o ensino da dança na escola deve estar vinculado a aspectos motores, sociais, cognitivos, afetivos, culturais, artísticos, pois como atividade pedagógica tem a função de superar uma cultura corporal voltada para execução de movimentos já preestabelecidos, produzidos pela humanidade.

\section{ENSINO DA DANÇA ESCOLAR}

No desenvolvimento histórico, a educação escolar tem privilegiado valores intelectuais em relação a valores corporais. Nessa esfera de entendimento, Silva e Damiani (2005) abordam que a trajetória da sociedade foi construída numa perspectiva inadequada em relação à valorização da Cultura Corporal. Trazendo essas considerações para o escopo deste artigo, verifica-se que, no ambiente escolar há uma discriminação em relação às disciplinas artísticas, ${ }^{4}$ que são realizadas de forma mais lúdica. A crítica aponta nelas a ausência de seriedade, conferindo-lhes um caráter supérfluo.

$\mathrm{Na}$ contramão dessa crítica, há que se considerar que é impossível negligenciar uma educação que considere o corpo como um instrumento de valor, já que o indivíduo age no mundo, por meio do seu corpo. É o corpo que serve como veículo de expressão, comunicação, apreensão e compreensão de uma realidade. As manifestações artísticas figuram como propulsoras desse veículo e refletem em recurso auxiliar na formação do indivíduo, uma vez que tratam o corpo na sua totalidade.

A visão tradicional da cultura corporal, entretanto, vem se modificando. Alguns estudiosos da área elucidam que, atualmente, existe uma melhor compreensão dos valores formativos e criativos da dança, que levam a uma ampliação das ações corporais.

É importante, assim, que a prática da dança com objetivos educacionais tenha início na escola. Nessa perspectiva, Pereira et al. colocam que:

\footnotetext{
${ }^{4}$ Estas disciplinas utilizam conteúdos como: teatro, música, dança, arte cênica, que valorizam a cultura do movimento, enquanto uma das formas de aprendizagem

Movimento, Porto Alegre, v.13, n. 02, p.155-171, maio/agosto de 2007.
} 
[...] a dança é um conteúdo fundamental a ser trabalhado na escola: com ela, pode-se levar os alunos a conhecerem a si próprios e/com os outros; a explorarem o mundo da emoção e da imaginação; a criarem; a explorarem novos sentidos, movimentos livres [...]. Verifica-se assim, as infinitas possibilidades de trabalho do/para o aluno com sua corporeidade por meio dessa atividade. (PEREIRA et al., 2001, p 61)

Desse modo, autores como Marques (2003), Sborquia e Gallardo (2006) e Strazzacappa e Morandi (2006) descrevem a importância do processo de escolarização da dança. Ressaltam que, por meio de um trabalho consciente de dança, a escola terá condições de formar indivíduos com conhecimento de suas possibilidades corporal-expressivas. Partilhando da mesma idéia, Vargas (2003) argumenta que a dança na escola situa-se como temática da Cultura Corporal, como linguagem expressiva.

A dança é importante para a formação humana, na medida em que possibilita experiências dos(as) alunos(as), bem como proporciona novos olhares para o mundo, envolvendo a sensibilização e conscientização de valores, atitudes e ações cotidianas na sociedade.

Assim, fomentar a educação, por meio da dança escolar, não se resume em buscar sua execução em festas sazonais, tampouco oferecer a idéia de que dançar se faz dançando, numa visão de dança apenas como passatempo, muito menos centralizada na espetacularização e no aprimoramento técnico (SBORQUIA e GALLARDO, 2006). Para esses autores, o estudo e a compreensão da dança corporal vão muito além do ato de dançar.

Uma proposta de dança escolar, em consonância com os autores já referidos, resume-se em buscar uma forma de dança livre do academicismo, mostrando que não se restringe apenas ao aprendizado de técnicas e estilos, como ballet clássico, jazz, moderno entre outros, ela vai bem além de uma simples classificação.

Por outro lado, não se trata de negar essas artes tradicionais, implica uma perspectiva de arte não só para ser contemplada e admirada à distância, mas para ser aprendida, compreendida,

Movimento, Porto Alegre, v.13, n. 02, p.155-171, maio/agosto de 2007. 
experimentada e explorada, numa tentativa de levar o indivíduo a vivenciar o corpo em todas suas dimensões. Remete a dança como atividade capaz de ampliar o rol de conhecimentos de um indivíduo, pela relação consigo mesmo, com os outros e o mundo, no desenvolvimento das suas potencialidades humanas. Enfim, permitindo uma maior acessibilidade da população a essa linguagem.

No que diz respeito aos conteúdos que visem a uma educação do/e pelo movimento para compreensão da dança, Marques (2003, p. 31) ressalta que:

[...] os conteúdos específicos da dança são: aspectos e estruturas do aprendizado do movimento (aspectos da coreologia, educação somática e técnica), disciplinas que contextualizem a dança (história, estética, apreciação e crítica, sociologia, antropologia, música, assim como saberes de anatomia, fisiologia e cinesiologia) e possibilidades de vivenciar a dança em si (repertórios, improvisação e composição coreográfica).

Percebe-se que o campo de abrangência desses conteúdos é rico e diversificado, porém não deve ser entendido como "receita de bolo", em uma visão tradicional. Deve, sim, ressoar como auxiliar, acrescentando ao processo de ensino-aprendizagem aspectos diretamente relacionados ao corpo, à dança, à pluralidade cultural, levando sua prática a uma (re)leitura de mundo totalmente voltada para nossa realidade histórica e social.

A partir desses pressupostos, Sborquia e Gallardo (2006, p.102) também refletem sobre os conteúdos numa perspectiva de não considerá-los estáticos e acabados, "pois são conteúdos dinâmicos, articulados, dialeticamente com a realidade histórica", devendo ser conduzidos de forma que transmitam uma cultura já existente e que ao mesmo tempo contribuam para novos conhecimentos. Acima que de tudo, a escola deve estar sensível aos valores e vivências corporais que o indivíduo traz consigo, permitindo dessa forma que conteúdos trabalhados tornem-se mais significativos.

Nesse sentido, Marques (2003) aborda que, para se fazer escolhas significativas, seria interessante levarmos em consideração

Movimento, Porto Alegre, v.13, n. 02, p.155-171, maio/agosto de 2007. 
o contexto dos alunos, respeitando suas próprias escolhas, opiniões, criações e possibilidades, para a formação de cidadãos com uma visão mais crítica, autônoma e participativa desta sociedade em que vivemos.

\title{
3 DANÇA NO CONTEXTO DA EDUCAÇÃO FÍSICA
}

A importância e o significado da Educação Física implica reflexões sobre seus paradigmas, pois o formato dinâmico desta sociedade requer dessa área a capacidade de abordar múltiplos conhecimentos produzidos e usufruídos a respeito do corpo. Na fala de Pinheiro:

\begin{abstract}
A Educação Física, desenvolvida de forma consciente, respeita as diferenças [...], ou seja, as individualidades de cada um e não dicotomiza o ser humano, não separando o corpo físico do mental, entendo que ambos funcionam de modo integral. (PINHEIRO, 2004 p. 32)
\end{abstract}

Assim sendo, a Educação Física, como área do conhecimento e disciplina curricular, não pode estar aquém de um saber sistematizado, contextualizando o indivíduo no seu próprio meio, por meio da teoria e da prática educacional. Nesse propósito, a dança apresenta-se como uma das atividades completas por concorrer de forma acentuada para o desenvolvimento integral do ser humano.

Cabe ressaltar que Strazzacappa e Morandi (2006) fazem considerações pertinentes em relação à valorização da Cultura Corporal, pela linguagem da dança; entretanto, suas colocações referem-se ao profissional intitulado de "artista da dança", ${ }^{5}$ que possui como formação, a Licenciatura em Dança, e de acordo com ela, é o profissional mais habilitado para trabalhar nesta área, na escola.

O Brasil é um país com muitas realidades. Enquanto a dança no Sudeste e Nordeste já é cinqüentenária, ${ }^{6}$ no Sul do país, mais precisamente na região de Santa Florianópolis , Catarina, sequer existe a oferta de graduação nessa área. Diante dessa realidade, uma das

${ }^{5}$ Nomenclatura utilizada pela Legislação Educacional, para designar o Licenciado em Dança. ${ }^{6}$ De acordo com Strazzacappa (2006), a primeira Universidade de dança surgiu em 1956, na Bahia.

Movimento, Porto Alegre, v.13, n. 02, p.155-171, maio/agosto de 2007. 
possibilidades em regiões como a citada, é buscar no universo da Educação Física uma forte inserção da dança como atividade educativa.

Nesse sentido, Sborquia e Gallardo (2006) elaboram seu pensamento, entendendo que a dança faz parte do contexto da Educação Física, constatando que, durante muito tempo, essa área do conhecimento esteve preocupada com movimentos estereotipados e no melhor desempenho. Hoje alguns caminhos a levam a almejar qualidade de se expressar.

Fica evidenciada, também, a importância da dança na Educação Física, quando Saraiva et al. destacam:

No caso da Educação Física, parece fundamental oferecer alternativas de práticas corporais na busca de englobar o ser humano de forma mais ampla, permitindo aos envolvidos que sejam participantes ativos no processo de aprender e fazer em dança. (SARAIVA et al., 2005, p.131)

Pensar numa escola emancipadora, portanto, é pensar em um espaço não apenas de escuta, mas de permanentes expressões, representações, construções e criações, capaz enxergar a prática pedagógica da Educação Física, interagindo com linguagem corporal nas diferentes possibilidades que a dança traz. Esse diálogo realizado com o corpo, por meio da dança, permitirá, de acordo com Barros (2003, p. 29), a otimização das "[...] possibilidades e potencialidades de movimento e a consciência corporal para atingir objetivos relacionados com a educação, expressão corporal e artística".

Dessa forma, também o profissional de Educação Física terá uma opção a mais a para a sua atividade, auxiliando-o na construção de um currículo diversificado, ao alcance de seus objetivos. Isso só vem mostrar quão rica de oportunidades é a área da Educação Física.

Para que a proposta curricular, entretanto, tenha o efeito desejado pelo professor, enriquecendo sua prática e servindo como instrumento transformador, é necessário que este não aceite propostas já predeterminadas, sem antes "questioná-las, discuti-las, compreendê-las, modificando-as e adaptando-as sempre que necessário" (BARBOSA, 2001, p. 93).

Movimento, Porto Alegre, v.13, n. 02, p.155-171, maio/agosto de 2007. 
Em consonância com a essa abordagem, Pereira et al., asseveram que:

\begin{abstract}
Para que esses objetivos sejam alcançados em aulas de dança na escola, o conteúdo desenvolvido deve caracterizar-se por uma lógica didática com relação a seus objetivos, à organização dos conteúdos, à escolha metodológica, aos procedimentos a serem tomados. Sobretudo, todas essas decisões devem ser tomadas sob uma concepção de educação e, portanto, de Educação Física, para que efetivamente o professor venha a escolher o caminho correto para a consecução dos seus objetivos educacionais. (PEREIRA et al., 2001, p. 60)
\end{abstract}

Faz-se importante ressaltar que, apesar dos benefícios comprovados descritos neste artigo, a prática da dança nas aulas de Educação Física ainda se realiza de forma muito restrita. Isto se dá, principalmente, devido ao despreparo na formação dos profissionais. Embora a dança tenha crescido nas principais universidades, de nosso país, ainda é pouco explorada no âmbito escolar. As universidades, principalmente na área da Educação Física, podem incluir em seus currículos estudos teórico-práticos e didático-pedagógicos da dança para suprir as necessidades dos profissionais interessados em trabalhar com ela.

Cumpre destacar que, em relação ao panorama dos cursos de Educação Física, Strazzacappa e Morandi (2006) referem-se a um enfoque reduzido nos conteúdos da dança, em relação a outros da área, decorrente da existência de apenas uma disciplina em um semestre, na maioria dos cursos, trazendo disso o sentimento de insegurança para os alunos que alegam não se sentirem aptos a trabalhar com o conhecimento da dança na escola.

Também Sborquia e Gallardo (2006) apontam essa realidade afirmando que isso se dá devido aos cursos de Licenciatura em Educação Física utilizarem "apenas os conteúdos das modalidades esportivas na formação de futuros professores".

Rangel também faz referência à dança como área pouco utilizada na Educação Física:

Movimento, Porto Alegre, v.13, n. 02, p.155-171, maio/agosto de 2007. 
É certo que a pouca utilização desta atividade em
propostas escolares pode ser um reflexo de sua
situação nos cursos de graduação em Educação
Física (licenciatura), da visão que os graduandos
têm a respeito da dança e, conseqüentemente, do
enfoque que a mesma tem recebido. (RANGEL,
2002 , p. 61)

Outro aspecto que agrava a situação apontada é a ausência de espaço físico, na maioria das escolas atrelado ao fato de que, muitas vezes tanto o professor de Educação Física como, em muitos casos, os pedagogos vêm trabalhando com a dança sem estarem preparados para isto. É preciso que se entenda que a dança na escola é considerada como área do conhecimento e, como tal, precisa ser estudada, compreendida, vivenciada e não ser restringida ao mero entretenimento. Talvez a ausência de uma reflexão mais significativa da dança acarrete esses problemas. Esse é, sem dúvida, um dos pontos mais críticos.

Marques (1999), também se referindo ao profissional que vai atuar com a dança, ressalta que o ensino universitário, nessa área, não supre as necessidades do mercado, deixando a entender que talvez seja necessária maior compreensão e comprometimento por parte desses profissionais com relação a seu entendimento da dança. O fato é que compreender o corpo por meio da dança, como possibilidade de estabelecer múltiplas relações com outras áreas do conhecimento, analisando, discutindo, refletindo e contextualizando seu papel na contemporaneidade, passa a ser condição para quem trabalha com seres humanos, principalmente para quem trabalha na educação, em que a multiplicidade de corpos está presente nas salas de aula.

\section{CONSIDERAÇÕES FINAIS}

No transcorrer deste artigo, enfocou-se a dança e a escola, dança na escola, dança com a Educação Física, enveredando as reflexões para os caminhos da educação.

A dança inserida na disciplina de Educação Física, de acordo com autores aqui citados, favorece a possibilidade da elaboração de um currículo não restrito ao ensino do desporto e abre espaço

Movimento, Porto Alegre, v.13, n. 02, p.155-171, maio/agosto de 2007. 
para se trabalhar a dança em suas diferentes abordagens. Além disso, favorece também o profissional de Educação Física que terá um aporte teórico cada vez mais fundamentado para sua formação. Nesse contexto, esse profissional liberta-se do estereótipo de que seu único espaço de atuação são as quadras de esporte, identificandose cada vez mais como educador.

Por essa razão, torna-se necessário um estudo para verificar as condições que são oferecidas pelos cursos de formação, no sentido de proporcionar aos professores as condições para que incluam em suas atribuições docentes a prática da dança na Educação Física, de forma que se criem, também, oportunidades educativas para o aluno vivenciar atividades como a dança.

Essas discussões apontam para o compromisso que deve ter o educador da área da educação física, assumindo uma atitude consciente na busca de uma prática pedagógica mais coerente com a realidade, buscando na dança uma oportunidade de levar o indivíduo a desenvolver sua capacidade criativa, numa descoberta pessoal de suas habilidades, contribuindo de maneira decisiva para a formação de cidadãos críticos, autônomos e conscientes de seus atos, visando a uma transformação social.

Ressalta-se a importância da estruturação de um bom trabalho de dança nas escolas, o que implica o envolvimento da disciplina educação física e da comunidade escolar, construindo um comprometimento abrangente e um compartilhamento de idéias, em benefício da coletividade. Sabe-se que os trabalhos advindos dessa proposta atestam a garantia de uma educação de responsabilidade de todos por uma educação de qualidade.

Entende-se também que as experiências realizadas precisam ser socializadas, debatidas e sistematizadas para que cada vez mais se tenha uma visibilidade da Pedagogia da dança, como algo que se diferencia do modelo escolar tradicional.

Espera-se que este estudo leve a conexões, novas idéias, discussões, sobretudo do aprofundamento do conhecimento da dança, contemplando, também, a atuação enquanto professor, visando cada vez mais à autonomia profissional, na busca de uma formação

Movimento, Porto Alegre, v.13, n. 02, p.155-171, maio/agosto de 2007. 
acadêmica mais coerente com a realidade do processo educativo e social.

School dancer: a possibility in the physical
education
Abstract: The present article shows some
considerations about the dance, dance in the soci-
al acting, dance associated with the education
process; detach important information that must
be discuss with the teachers of the Physical
Education, having thorough the dance the corporal
comprehension and the relationship with another
areas of knowledge. Emphasize the obstacles, to
pass over, to the dance take its place more and
more in the school area. These considerations make
firm the compromise that the educator, must have
in search of a pedagogical practice to form critical
citizens, independents and conscious with their
acts, to a social transformation.
Keywords: Dancing. Physical education. Teaching.
Cultural evolution.

\begin{tabular}{l} 
Danza escolar: una posibilidad en la \\
educación física \\
Resumen: El presente articulo relata las reflexiones \\
con respecto a la danza, su actuación en la sociedad \\
y su comprensión asociada al proceso educacio- \\
nal; destaca informaciones primordiales que deben \\
ser abordadas y discutidas con el profesor de \\
Educación Física, dirigidas hacia el proceso de \\
comprensión corporal a través de la danza, como \\
posibilidad de establecer múltiples relaciones con \\
otras áreas del conocimiento. Hace referencia con \\
énfasis a los enfrentamientos, así como a las \\
barreras a seren quebradas, para que la danza \\
este cada vez mas incluida en el ambiente escolar. \\
Estas discusiones se refiren al compromiso que debe \\
tener, el educador, en busca de una práctica peda- \\
gógica direccionada a la formación de ciudadanos, \\
críticos, autónomos y concientes de sus actos, para \\
una transformación social. \\
Palabras clave: Danza. Educación Física. \\
Enseñanza. Evolución cultural. \\
\hline
\end{tabular}

\section{REFERÊNCIAS}

BARBOSA, Cláudio L. de Alvarenga. Educação Física escolar: da alienação à libertação. 3. ed. Petrópolis: Vozes, 2001.

Movimento, Porto Alegre, v.13, n. 02, p.155-171, maio/agosto de 2007. 
BARROS, Joseane Maria de C. Considerações sobre o estágio na formação do profissional de educação física. Revista E.F., Rio de Janeiro, v. 2, n. 8, p. 28-31, 2003.

BARRETO, Débora. Dança...: ensino, sentidos e possibilidades na escola. São Paulo: Autores Associados, 2004.

FAHLBUSCH, Hannelore. Dança moderna-contemporânea. Rio de Janeiro: Sprint, 1990.

GARIBA, Chames Maria Stalliviere. Personal Dance: uma proposta empreendedora. 2002. 133f. Dissertação (Mestrado em Engenharia de Produção) - Universidade Federal de Santa Catarina, Florianópolis, 2002.

MARQUES, Isabel. A. Ensino da dança hoje: textos e contextos. São Paulo: Cortez, 1999.

Dançando na escola. São Paulo: Cortez, 2003.

NANNI, Dionísia. Dança educação: princípios métodos e técnicas. 2. ed. Rio de Janeiro: Sprint, 1998. Sprint, 2003

Dança educação: pré-escola a universidade. 2. ed. Rio de Janeiro:

OLIVEIRA, Valter M. de. O que é educação física. São Paulo: Brasiliense, 2001.

PEREIRA, Silvia Raquel C. et al. Dança na escola: desenvolvendo a emoção e o pensamento. Revista Kinesis, Porto Alegre, v.2, n. 25, p.60-61, 2001.

PINHEIRO, D. R. V. O perfil do personal trainer na perspectiva de um treinamento físico orientado para saúde, estética e esporte. Disponível em: <http://www.personaltraining.com. br/teseresumo.htm>. Acesso em: 7 fev. 2004.

RANGEL, Nilta Barbosa Cavalcante. Dança educação, educação física: proposta de ensino da dança e o universo da educação física. Jundaí: Fontoura, 2002.

ROBINSON, Jaqueline. Le languange choégraphique. Paris: Vigot, 1978.

SARAIVA. Maria do Carmo et al. Dança e seus elementos constituintes: uma experiência contemporânea. In: SILVA, Ana Márcia; DAMIANI, lara Regina (org.). Práticas corporais: Experiências da Educação Física para a outra formação humana. Florianópolis: Nauemblu Ciência \& Arte, 2005. v.3, p.115-133.

SBORQUIA, Silvia. P.; GALLARDO, Jorge S. Pérez. A dança no contexto da educação física. ljuí: UNIJUÍ, 2006.

Movimento, Porto Alegre, v.13, n. 02, p.155-171, maio/agosto de 2007. 
SILVA, Ana Márcia; DAMIANI, lara Regina (org.). Práticas corporais: gênese de um movimento investigativo em Educação Física. Nauemblu Ciência \& Arte, Florianópolis: v.1, p.17-23, 2005.

STRAZZACAPPA, Márcia. A educação e a fábrica de corpos: a dança na escola. Caderno Cedes: dança educação, São Paulo, v. 21, n.53, p.1-10, abril 2001.

STRAZZACAPPA, Márcia; MORANDI, Carla. Entre a arte e a docência: a formação do artista da dança. São Paulo: Papirus, 2006.

SURDI, Bernadete M. M. Corporeidade e aprendizagem: o olhar do professor. ljuí: UNIJUÍ, 2001.

VARGAS, Lisete Arnizaut. A dança na escola. Revista Cinergis, Santa Cruz do Sul, v.4, n.1, p.9-13, jan/jun. 2003.

Recebido em: 03/04/2007

Aprovado em: 26/05/2007

Movimento, Porto Alegre, v.13, n. 02, p.155-171, maio/agosto de 2007. 